\title{
Natural Disaster Insurance, Problems of Capacity and Solvency
}

\author{
by Bruno Porro*
}

\section{Introduction}

The topic demands that we first define or at least clearly delineate the concepts to be dealt with, in order to found discussions on a base of uniform terms. This seems but is not lapidary - not in this interdisciplinary field, where one word could have several totally different meanings depending on the training of the reader. Risk may be one building and its contents to the fire insurer, whereas the seismological engineer could name the product of hazard times vulnerability as the appropriate explanation.

This working group comprises not only representatives of the insurance industry. First, we should therefore go into those basic principles of insurance that are relevant when discussing capacity and solvency. In particular the interaction of insurance and reinsurance merits a closer look.

In the interest of a discussion in more concrete terms, it is preferable to stick to one natural hazard and a given insurable interest. Property covered against earthquake will serve as our example of illustrating basic methods.

\section{Some notions of insurance and reinsurance}

A property insurance policy represents a contract between the insured and the insurer, who, in consideration of a premium, covers the insured against financial loss through damage to property by defined hazards, at conditions that figure in the policy.

In a fire policy, for example, you will encounter the following concepts :

- The insured value (sum insured) of the property, e.g. the reconstruction cost of a building.

- The condition of average, which states that, if the sum insured is materially lower than the actual value, indemnities shall be reduced in like proportion.

* Swiss Reinsurance Company, Zürich. 
- The deductible, either in percent of the sum insured or as a fixed amount, which the insured must bear as a first loss in each and every claim. This excludes trifling losses from the cover and entitles to a premium discount, unless it is a general feature.

- The definition of cover specifying the hazards covered and the exclusions.

Several policies may be affected by the same fire, e.g. contents policies of several insured in the same building or policies covering several buildings which are close together. In order to limit his liabilities in case of loss to a maximum amount, the insurer must exercise a control over the issued policies. He must check, for each new acceptance, whether it can be affected together with other policies by the same fire and whether the resulting loss could overshoot his financial resources. All policies that cumulate with each other form a risk unit for the fire insurer with a corresponding total sum insured.

Here we encounter for the first time the concept of capacity, in the form of the amount of loss that the insurer will have to pay, if all the cumulating policies become total losses. It is the disbursement on a single loss that the insurer will want to keep within his means. Such loss capacity is a fixed amount, but what it will absorb depends on what must be considered as cumulating, i.e. as forming a single risk, and this in turn will depend on the nature of the buildings, the fire hazard, the measures of prevention, the use and occupancy and other factors. Seen in this light, capacity is not rigidly fixed a priori.

In practice, cumulating sums insured are not the only basis of application. For larger industrial complexes an estimated maximum loss is often worked out as a basis for using capacity.

Such maximum loss estimates are based on the expectation that certain concomitant conditions will prevail (such as for example : normally operating alarm and loss prevention systems, no unusual delay in fire fighting or the arrival of the fire brigade).

Capacity can be increased materially by reinsurance, in that the insurer buys reinsurance cover from reinsurers. There are three basic ways to do this :

- Under a quota-share treaty the insurer retains a uniform percentage of each policy or risk unit, an equally uniform percentage being ceded to the treaty reinsurers. A retained quota of $20 \%$, for example, means five-fold capacity to the insurer. Increasing insurer's capacity is only one of the functions of reinsurance.

- Under a surplus treaty not a uniform quota, but an amount (retention) is fixed, which the insurer will keep of each risk unit for his own account. (This amount can be varied according to various risk evaluation criteria $\rightarrow$ table of limits.) The treaty reinsurers automatically accept the surplus over and above this retention up to a maximum multiple of the insurer's retention. In contrast to the quota-share treaty, the subject-matter of the reinsurance cover is reduced to those risk units the amount of which exceeds the retention.

- An additional protection for the retention is afforded by the excess of loss treaty, which takes care of that part of each loss which exceeds a certain figure, the deductible.

\section{Insurance and natural hazards}

By itself the conclusion of a policy does not alter the vulnerability of the insured property. The insurance industry simply transfers money from the many who pay 
premiums to the few who suffer loss. (This is, of course, a relative statement : in many cases insurers do request improvements in the risk, which reduce its vulnerability. Conversely, the existence of a policy may increase the probability of a loss occurring, such as fraud by arson.)

In fire insurance, for example, the premiums are fixed in accordance with criteria related to the loss experience of more or less homogeneous groups of risk units. The number of risk units or claims observed, i.e. the size of the portfolio, decisively affects the relevance of statistical data, such as :

- average loss amount;

- average lapse of time between two losses.

For the same reason, the size of the sample (the portfolio) is relevant to decisions affecting business policy taken within the scope of supervisory legislation.

One essential contrast to natural hazards is that ordinary fire insurance can fall back on empirical loss data for the purpose of fixing a price on the basis of actual experience. Let us now try and list some main points of difference between fire insurance and our natural hazard example, earthquake cover :

- In fire, it is possible to fix independent risk units in such a way, that one single event will not affect several. Thus the amount of loss under most unfavourable circumstances can be limited effectively to a certain figure. A single earthquake will, however, affect many of these fire risk units simultaneously.

- For a single risk unit, the frequency of loss is small also in fire insurance. It increases, however, with a growing number of risks. With earthquake, however, the event frequency is small even for the whole portfolio of risks, as large as it may be.

- The area affected by a single event is less than $1 \mathrm{~km}^{2}$ with respect to fire. An earthquake can cause damage to buildings scattered over thousands of square kilometers.

These differences entail the following consequences:

- Individual risk units are no longer independent of each other with respect to an earthquake event, the risk unit must be redesigned to fit catastrophic exposure. By doing so, the requirement of large numbers is practically lost.

- Relative fluctuation, which reduces for fire as the portfolio increases, remains practically independent in earthquake of the number of policies.

- Loss experience is no basis for assessing earthquake risk premiums.

It is evident that earthquake (on a par with other natural hazards) calls for an insurance technique of its own, which takes into account the particularities of this hazard. This includes special consideration of questions concerning capacity and solvency.

\section{The assessment of the earthquake risk}

In contrast to fire insurance, we define as risk in respect of earthquake the product of hazard, vulnerability and insured values. The same earthquake risk can thus arise for the same level of vulnerability from a small hazard and a high insurance density or vice versa. Let us therefore first discuss the elements that compose the earthquake risk individually. 


\subsection{Hazard}

What is the yardstick we shall use for measuring the hazard? Magnitude (in several variations) seems to present the advantage of instrumental measurement and thus to constitute a more objective gauge of the hazard than intensity (modified Mercalli or MSK), which rests on subjective judgment. On the other hand, magnitude has no direct relationship to the values at risk: A strong and distant earthquake can produce damage of the same order of importance as a small earthquake close by, although the effects can be rather different. Or, in other words, magnitude is no proper scale for the hazard, as damage will depend on the epicentral distance. Further drawbacks of instrumental observation data consist in incomplete registration and the short period of observation. Intensities also must be viewed critically, but they do permit the inclusion of macroseismic observations in the more distant past and an increase in the number of observations at least in the higher intensity ranges. Empirical correlations between hazard and vulnerability are only known as functions of intensity. The same is true for the area distribution of the effects of one given earthquake, that can vary from total destruction to mere detection. Such data are indispensable for calculating the loss potential. Thus, we have no choice but to put up with the imprecise yardstick of intensity, until better methods and scales are available. In any case, we must accept to live with considerable uncertainties, particularly in regions with little seismic activity and/or unreliable instrumentation. In this connection, we must also refer to the suspected existence of world-wide and regional trends in seismicity, which could severely curtail the relevance of observation using statistical methods.

\subsection{Vulnerability}

As a sequel to fixing a scale for the hazard let us define vulnerability as the average damage degree (expressed in percent of values at risk) as a function of the degree of intensity. This in turn presupposes that there is a sufficiently large number of insured objects, to permit calculating with averages. Vulnerability is best analysed separately for the following sectors:

\section{- Buildings}

The vulnerability of buildings to damage by earthquake depends on many factors, the most important of which are enumerated: Dimensions, building materials, their dynamic behaviour and interaction, building code and design philosophy, age, soil-structure interaction, weakening through earlier earthquakes, workmanship, quality of bonding. These factors influence shock damage directly. Indirect losses can result principally from soil liquefaction, settlement of the subsoil and landslides. As most earthquake insurances also cover fire following, the fire hazard, as it will present itself in an earthquake event, also has to be taken into account (e.g. seepage of combustible liquids or gases, fracturing and leakage of pipes and vessels, open fires or fire out of its normal confines, short circuit).

- Contents

With respect to the insurance of contents values within buildings, the following factors materially affect damage ratios: stability of values and their storage, mounting and bracing, impact strength, state of aggregation, deformability. At lower intensities, the vulnerability of contents can be regarded as practically independent of damage to the 
building. Higher intensities, however, call for consideration of the earthquake properties of the building, as generation of dust, falling debris, collapse of partitions and false ceilings, partial and total collapse of roof or building all may considerably affect damage to contents.

- Business interruption

Covering business interruption following earthquake is an extremely tricky matter. The risk is very hard to evaluate, as the extent and duration of the interruption strongly depend on the production process, which buildings and machinery have been damaged and to what extent, as well as external factors such as the lag of fire brigade intervention, the availability of replacements, spare parts, building materials and manpower after the catastrophe. Depending on the severity of the event, a region might undergo a phase of paralysis, and this in itself can negate one of the prime conditions of the business interruption policy, i.e. the endeavour on the part of the insured to reinstate his business to its prior condition as soon as possible.

\subsection{Insured values}

Apart from the vulnerability of the insured values (which in turn depends on the factors described above), the importance of the risk in terms of money is also affected by the geographical scattering of the sums insured. Concentrations of high total values within small areas can be heavily affected by a single seismic event, where insured values are spread more or less evenly over larger areas, the threat of a bull's eye hit is less prominent. According to whether we are looking at a hit or miss as opposed to a situation of spread values, we obtain entirely different damage ratio/frequency distributions. A single concentration produces a relatively low frequency of hits combined with relatively high damage, a broader spread will be subject to a greater frequency of occurrence, but the resulting event damage will tend to be smaller.

\section{Interline accumulation}

We have demonstrated the evaluation of the earthquake risk using the example of fire insurance. As a rule, insurance companies do not limit their activities to the line, but offer cover also in others : accident, liability, engineering, motor, marine, life, aviation to name the most important. The event damage resulting from an earthquake, for example, will therefore in most cases represent an accumulation of loss from several lines, for which insurers and reinsurers have to respond. As we have seen, the evaluation of the earthquake risk arising from fire insurance is no easy matter. The difficulties increase when estimating the event damage that could result from several lines together:

The time of occurrence has much impact on the amount of damage. An earthquake at 2 a.m., when most people are at home, will not affect the workmen's compensation cover of employers. If the same earthquake occurs, however, at 3 p.m. and causes collapse of factory buildings, the death of or injuries to many workmen can produce an enormous claim in this line. Other examples are seasonal variation of hotel occupancy (Budva, Yugoslavia, 1979 and Loutraki, Greece, 1981) or seasonal variations of the fire following hazard. 


\section{Accumulation of several events}

By this, we mean the occurrence of several catastrophic losses within a relatively short time (a few years). This could be a series of earthquakes or even an accumulation of events arising from different hazards and affecting various lines (e.g. earthquake in Japan, windstorm in the U.S.A., major fire in Germany, hailstorm in South Africa, flood in London, epidemic in India). The threat of accumulations of events is of particular importance for insurers and reinsurers active on an international scale.

\section{Factors affecting capacity}

We now understand that a clear-cut standard definition of capacity does not exist. But perhaps it is possible to demonstrate what are the main factors of influence on the capacity of an international risk carrier. Our starting point are the two-way relationships between risk carriers, which link insurer with reinsurer, reinsurer with retrocessionaire and often let the same company have its part in all three rôles.

The treaties concluded between such partners have already been touched upon in section 2 . The conditions are either negotiated directly between the parties or arranged by a broker. One treaty is as a rule placed with several reinsurers or retrocessionaires, and the activity of a company can either be confined to one particular market or exercised on an international scale.

\subsection{Information}

As the first factor of influence on capacity, we want to discuss the nature and extent of information on the business written, using once more the example of earthquake insurance.

It is obvious that only those companies who write the business direct (or the insurance broker) have full information on the individual risk unit at their disposal (such as sum insured, location, type of construction, scope of cover, etc.). Reinsurers - at least in respect of business under automatic treaties, which cover whole portfolios of risk units - only know the maximum retentions of the ceding company and the maximum capacity of the treaty for each category of risks, as well as the general underwriting instructions. The retrocessionaire is even worse off, as he often participates in a mix of treaties. The results of fire business, if it is reasonably well-balanced, become apparent after a few years and corrective measures can be taken, if necessary. Even in this line, however, the need has become apparent for the reinsurer to dig deeper and analyse such aspects as the rating level, the composition of the portfolio, its loss pattern.

Going from fire to earthquake, it is evident that analysing results becomes almost useless and the need for other types of information, such as data on exposure, becomes predominent. It is a salient feature of earthquake that many risk units can be affected by the same occurrence. The reinsurer (and his retrocessionaires) must have a way of ascertaining to what total amount the simultaneously exposed individual values add up. As one insurer has treaty connections with many reinsurers and one reinsurer with many ceding companies, it is indispensable to standardize all data required for earthquake risk 
evaluation and to present them throughout in the same way. An evaluation based on given criteria such as zone, type of cover, type of construction, currency, subject-matter presupposes that all accumulation reports under all treaties will be drawn up along the same principles and in accordance with the same split-up. It is this effort in favour of standardized data that has crystallized in the system called CRESTA ( = Catastrophe Risk Evaluating and Standardizing Target Accumulations).

The quality of the information varies from one market to another and within one market, from company to company. The range extends from no information at all or only occasional summary indications of the countrywide total to exact and regular reporting in accordance with the framework laid down by CRESTA. It needs hardly be mentioned that the better the reinsurer is informed, the more he can afford to write up to his full limit.

\subsection{Estimated maximum loss}

As we have seen, the hazard, the vulnerability and the geographical spread of the insured values materially affect the loss potential. Where the insured values are all concentrated within one city, the possibility (although it may be rather remote) always exists that all risk units become total losses, i.e. that total destruction generates an overall damage ratio of $100 \%$. The probability of such events is mostly small. The point is that the reinsurer, in order to be able to convert the accumulated earthquake liabilities into a maximum damage estimate, must fix a certain damage ratio. The decision as to the level of this key damage ratio will on the one hand depend, as we have seen, on the factors of hazard, vulnerability and spread of insured values. On the other hand, this decision also rests on the willingness of the enterprise to take risk. The smaller this risk willingness, the higher the damage ratio chosen and the smaller the capacity, as the fixing of capacity will normally start with an amount "Willing to lose", that is an amount in terms of loss. It should perhaps be added that the damage ratio/frequency distributions mentioned in section 4.3 provide a basis for entrepreneurial decisions as to the appropriate key damage ratio, as a company can, on the basis of such distributions, decide in respect of each catastrophe accumulation which frequency level it is willing to ignore for entrepreneurial purposes.

\subsection{Reserves and liquidity}

The enterprise should be able to meet all losses that arise in the course of its business activity from its own means, unless and in so far as it has covered part of such losses by way of retrocession. Reserves put aside to provide for catastrophic claims can take many forms and can range in practice from legal contingency and fluctuation reserves over special and free reserves to plus values and own capital. The form, in this context, is perhaps less material than the following points of principle :

- As lines can cumulate in a way which is difficult to forecast and several events can cluster within a few years, only a part of the total reserves available for catastrophes should be committed on earthquake in conjunction with fire. That is to say, catastrophe reserves should always bear a reasonable relationship to actual commitments.

- If, in these evaluations, credit is taken for retrocessional relief, the security should be checked most carefully.

- Claims-free catastrophe premiums should not be declared as profits, but used to feed catastrophe reserves. 
- The reserves should be invested in such a way that the catastrophes they are meant to cover will not affect the market price of the securities chosen for investment purposes. Additional measures may be necessary to ensure that securities will not have to be sold in a buyers' market, or at a bad rate of exchange. It is obvious that these aspects include proper attention to currency management, as rates of exchange can also be affected by major catastrophic events.

- As larger claims amounts will be payable after a catastrophe within a shorter lapse of time than usual, ample liquidity must be maintained for the purpose. This also should bear a reasonable relationship to actual commitments. Some companies establish scenarios of large catastrophes in advance, in order to make sure that handling will be smooth and swift along preorganized procedures.

- Last but not least, strenuous efforts must be undertaken to realistically evaluate commitments.

It is obvious that all these points strongly argue the case for adequate catastrophe rates, international as opposed to national coverage of catastrophe risks, and stable currencies. It is a pity that supervisory regulations generally do not seem to adequately cater for the particularities of catastrophic risks, but in many instances, by limiting the outflow of catastrophe premiums and by imposing deposits in national currency, rather seem to hamper the development of adequate capacity, instead of favouring it.

\subsection{Treaty conditions}

In some markets, fire and catastrophe premiums still cannot be properly separated. They are thus often subject to the same treaty conditions, including premium refunds based on short-term experience, although the nature of the two kinds of cover clearly demands separate evaluation based on entirely different criteria. In many a case deficitary fire business wears an appearance of profitability due to the presence of loss-free earthquake premiums.

\subsection{Market situation}

As other products, also insurance obeys the law of offer and demand. But unlike consumer and investment goods, the cost analysis of which clearly defines a lower price limit, insurance and particularly earthquake insurance has a rather uncertain profitability threshold. The insurance equivalent of production cost in the tangible goods industry, the losses, are very difficult to estimate and control in earthquake insurance. The lapse of time between setting up a tariff and the occurrence of the first losses can easily reach several decades. This can lead to cycles of low prices combined with high capacity levels (or, in other words, to an increased probability of ruin), as claims-free periods are mistaken for profitable ones. This is one of the reasons why judging the quality and security of reinsurers and retrocessionaires becomes an ever-more important matter, in such times of increasing capacity and escalating catastrophe exposures facing smaller reinsurance premiums.

\section{Summary}

The capacity of a company is not a fixed amount. Apart from other factors, own capital reserves, interest rates, opportunities for investment and market situation all have 
their bearing on aspects dealing with capacity and liquidity. As insurers, reinsurers and retrocessionaires fulfil their rôle as risk carriers together, it becomes even more difficult to try and determine total capacity, as these carriers are interdependent. Longer claims-free periods and periods af good results or high investment yields lead to increases in capacity, and, if this exceeds the requirements, to decaying prices. As price calculation in catastrophe insurance is in any case a process plagued with uncertainties, such trends occur all the more easily and remain all the harder to be laid open. We can renounce a description of the status quo in natural catastrophe insurance, as other papers will deal with this aspect.

\section{BIBLIOGRAPHY}

PERRENOUD, P., and STRAUB, E. : Insurance and the economic consequences of earthquakes, chapter 13 in "The assessment and mitigation of earthquake risk", UNESCO, Paris 1978.

J. H. WIGGINS COMPANY: “Earthquake Insurance Practices”, Technical Report No. 1388-2, Federal Insurance Administration, Washington 1981.

NÉGRIER, F. : La sécurité financière des compagnies d'assurances et de réassurances, L'ARGUS International (La Réassurance), Vol. 31 (juillet-août 1982), 222-238. 